\title{
Therapeutic Plasma Exchange in Parvovirus B19-induced Acute Hepatic Failure
}

\author{
Dhirendra P Singh ${ }^{1}$, Sheetal Agarwal ${ }^{2}$, Ruby Singh ${ }^{3}$, Devki Nandan ${ }^{4}$, Anubhav Gupta ${ }^{5}$
}

\begin{abstract}
Parvovirus B19 has rarely been associated with acute liver failure (ALF), which has a high mortality. Plasma exchange that usually acts as a bridge to liver transplantation removes toxins, antibodies, cytokines, and can correct coagulopathy while maintaining a euvolemic state. Pediatric data regarding its use are scarce. We report a case of 16-year-old girl with acute liver failure in stage 4 encephalopathy with coagulopathy due to parvovirus B19 who was successfully managed with high-volume therapeutic plasma exchange (TPE). We tried to use it as a treatment modality due to nonavailability of in-hospital transplant facilities. Parvovirus B19 may be an underdiagnosed cause of acute viral hepatitis. Therapeutic plasma exchange can act as a bridge to liver transplant (LT) or bridge to recovery especially in self-limiting illnesses such as viral hepatitis.

Keywords: Hepatic encephalopathy, Hepatic failure, Plasma exchange.

Indian Journal of Critical Care Medicine (2020): 10.5005/jp-journals-10071-23421
\end{abstract}

\section{INTRODUCTION}

Acute liver failure (ALF) is a life-threatening illness and has a high mortality without liver transplantation. Human parvovirus B19 is a single-stranded DNA virus belonging to the family parvoviridae, which causes various diseases including hepatitis. ${ }^{1,2}$ Parvovirus B19 has been rarely associated with fulminant hepatitis/liver failure in children and adults. ${ }^{3}$ Plasmapheresis that acts as a bridge to liver transplantation removes toxins, antibodies, and can correct coagulopathy while maintaining euvolemia. We report a case of 16-year-old girl with ALF due to parvovirus B19 who was successfully managed with therapeutic plasma exchange (TPE).

\section{Case Description}

A 16-year-old girl presented to emergency with complaints of pain in abdomen, vomiting, yellowish discoloration of eyes, and fever since 7 days. There was no history of taking aspirin and other known hepatotoxic drug/herbal medication. Her developmental history was appropriate for her age. There was no history of jaundice or anemia in past. On examination, her weight was $47.5 \mathrm{~kg}$ (between 25th and 50th percentile), height was $153 \mathrm{~cm}$ (between 25th and 50th percentile), temperature was $98^{\circ} \mathrm{F}$, heart rate $98 /$ minute, respiratory rate $24 /$ minute, and blood pressure was $100 / 70$. She was lethargic with the Glasgow coma scale (GCS) of 10 (E4V2M4), and pupils were normal size and normally reacting to light. Bilateral deep tendon reflexes were present and the Babinski sign was absent. Liver was $2.5 \mathrm{~cm}$, tender. The patient was shifted to PICU in view of hepatic encephalopathy. On arrival in PICU, the patient was in shock and had signs of increased intracranial tension (hyperventilation with irregular respiration and paradoxical breathing). The GCS had deteriorated to E1V1M4, pupils were normal size and normally reacting, tone was normal, deep tendon reflexes were absent, and the plantar reflex was flexor bilaterally. The patient was having altered blood aspirates from the nasogastric tube. Laboratory findings on admission were as follows: hemoglobin $-9 \mathrm{~g} / \mathrm{dL}$, total leukocyte count-6,000/ $\mathrm{mm}^{3}$ (25\% polymorphs and $65 \%$ lymphocytes), platelet count-1.2 lac, total bilirubin $-5.5 \mathrm{mg} / \mathrm{dL}$,

\begin{abstract}
${ }^{1-4}$ Division of Pediatric Pulmonology and Intensive Care, Department of Pediatrics, Atal Bihari Vajpayee Institute of Medical Sciences and Dr Ram Manohar Lohia Hospital, Delhi, India

${ }^{5}$ Department of Transfusion Medicine, Atal Bihari Vajpayee Institute of Medical Sciences and Dr Ram Manohar Lohia Hospital, Delhi, India

Corresponding Author: Sheetal Agarwal, Division of Pediatric Pulmonology and Intensive Care, Department of Pediatrics, Atal Bihari Vajpayee Institute of Medical Sciences and Dr Ram Manohar Lohia Hospital, Delhi, India, Phone: +919310034300, e-mail: drsheetalshah@ gmail.com

How to cite this article: Singh DP, Agarwal S, Singh R, Nandan D, Gupta A. Therapeutic Plasma Exchange in Parvovirus B19induced Acute Hepatic Failure. Indian J Crit Care Med 2020;24(5): 361-362.
\end{abstract}

Source of support: Nil

Conflict of interest: None

direct bilirubin-3.5 mg/dL. Aspartate transaminase (AST)/alanine transaminase (ALT) (U/L) — 4949/3248, alkaline phosphatase-150 U/L. Prothrombin time-35.5, international normalized ratio (INR)3.5 , blood ammonia- $173 \mu \mathrm{mol} / \mathrm{L}$, blood lactate $-4.9 \mathrm{mmol} / \mathrm{L}$, serum albumin $-2.5 \mathrm{~g} / \mathrm{dL}$. The child was mechanically ventilated, shock was fluid responsive, and blood products were given as and when required. Other appropriate supportive care for ALF and hepatic encephalopathy was also initiated. Relevant investigations to find etiology of hepatitis including viral panel, Wilson's disease, and autoimmune hepatitis workup were sent.

On day 3 of admission, even after appropriate supportive care patient's encephalopathy did not improve; serum ammonia levels were persistently above $>150 \mu \mathrm{mol} / \mathrm{L}$ with deranged INR. Hence, we planned for high-volume plasma exchange. A total of three cycles of plasma exchange were done on alternate days with fresh frozen plasma and 1.5 times of total blood volume with the centrifugation technique on the optia spectra machine. Each plasma exchange session lasted for 4 hours except for first session in which the child became hypotensive, which required $20 \mathrm{~mL} / \mathrm{kg}$ normal saline bolus;

() The Author(s). 2020 Open Access This article is distributed under the terms of the Creative Commons Attribution 4.0 International License (https://creativecommons. org/licenses/by-nc/4.0/), which permits unrestricted use, distribution, and non-commercial reproduction in any medium, provided you give appropriate credit to the original author(s) and the source, provide a link to the Creative Commons license, and indicate if changes were made. The Creative Commons Public Domain Dedication waiver (http://creativecommons.org/publicdomain/zero/1.0/) applies to the data made available in this article, unless otherwise stated. 
other two sessions were uneventful. After two sessions of TPE, the child's clinical condition started improving, liver function tests improved with INR -1.31, and the blood ammonia level decreased to $63 \mu \mathrm{mol} / \mathrm{L}$. The child was successfully extubated after third session of TPE. At discharge, the child was completely asymptomatic with normal sensorium. Her serum sample came out to be positive for parvovirus B19 IgM and all other workup done to find out etiology of ALF was negative.

\section{Discussion}

Acute hepatitis is an uncommon manifestation of parvovirus B19 and may present as mild elevation in hepatic enzymes from fulminant hepatic failure to chronic liver failure. ${ }^{2}$ The course is generally self-limiting. Fulminant hepatic failure caused by parvovirus B19 is rare with only few cases reported in the English literature both in children and adults, some of which even required liver transplantation. ${ }^{4-6}$ The mechanism of hepatic injury caused by parvovirus B19 remains unclear but nonstructural protein (NS1) found on the N-terminal region of the genome, which is cytotoxic for erythroid cells, has been implicated. ${ }^{7}$

Acute liver failure is a life-threatening illness, with a survival rate of $10-40 \%$ without liver transplant (LT) depending on the etiology. ${ }^{8}$ The probable mechanism leading to various complications of ALF such as hepatic encephalopathy, multiorgan dysfunction, etc., is due to release of inflammatory cytokines causing a systemic inflammatory response. ${ }^{9}$ Plasma exchange is one of the liver support system that usually acts as a bridge to transplant in ALF. In TPE, large volume of plasma is removed from a patient, which is replaced by either fresh frozen plasma or albumin. Therapeutic plasma exchange also removes various toxins, pathological antibodies, immune complexes, and cytokines from the systemic circulation and may have an immune-modulatory effect also. ${ }^{10}$ Fresh frozen plasma replenishes coagulation factors, albumin, and immunoglobulins and helps to correct coagulopathy. Similarly, TPE removes toxic metabolites like bilirubin, ammonia, and other toxins that accumulate in severe liver failure leading to complications and hampering the recovery of hepatocytes. In a randomized trial conducted by Larsen et al. it was observed that plasmapheresis improves the liver transplantation free survival rate of patients with ALF, although the LT rate was not reduced. ${ }^{10}$ Singer et al. also observed that coagulation profiles of 49 children with ALF who underwent a total of 243 TPE significantly improved after TPE. They concluded that plasmapheresis improves coagulopathy, prevents bleeding complications while maintaining adequate fluid, electrolyte, and acid-base balance. ${ }^{8}$ However, PE is not the replacement for definitive therapy i.e., LT in severe ALF. Stahl et al. compared performance of high-volume TPE vs low-volume TPE and found comparable results. ${ }^{11}$ It has also been found to be safe and well-tolerated, and it improves the coagulation profile and liver function tests in critically ill liver disease patients. ${ }^{12}$

Liver transplant is not readily available in resource-limited settings like ours. Hence, we considered other treatment modality to tide over the acute phase while managing complications of severe ALF.
Therapeutic plasma exchange can facilitate recovery of failing liver by gaining time for regeneration of liver cells and can be used as an effective therapy for bridging to LT or bridging to spontaneous recovery in toxic injury or self-limiting disease as in our case.

\section{Conclusion}

Parvovirus B19 hepatitis/hepatic failure may be an underdiagnosed cause of acute viral hepatitis. Therapeutic plasma exchange is a safe and well-tolerated liver support system that can act as a bridge to LT or bridge to recovery especially in self-limiting illnesses such as viral hepatitis.

\section{Author Contributions}

Dhirendra P Singh and Ruby Singh were involved in drafting the manuscript and patient care; Sheetal Agarwal and Devki Nandan critically reviewed the manuscript and gave intellectual inputs.

\section{References}

1. Arista S, DeGrazia S, DiMarco V, DiStefano R, Crax A. Parvovirus B19 and "cryptogenic" chronic hepatitis. J Hepatol 2003;38(3):375-376. DOI: 10.1016/s0168-8278(02)00416-6.

2. Bihari C, Rastogi A, Saxena P, Rangegowda D, Chowdhury A, Gupta N, et al. Parvovirus b19 associated hepatitis. Hepat Res Treat 2013;2013:472027. DOI: 10.1155/2013/472027.

3. Hillings $\varnothing \mathrm{JG}$, Jensen IP, Tom-Petersen L. Parvovirus B19 and acute hepatitis in adults. e Lancet 1998;351(9107):955-956. DOI: 10.1016/ S0140-6736(05)60609-5.

4. Krygier DS, Steinbrecher UP, Petric M, Erb SR, Chung SW, Scudamore $\mathrm{CH}$, et al. Parvovirus $\mathrm{B} 19$ Induced hepatic failure in an adult requiring liver transplantation. World J Gastroenterol 2009;15(32):4067-4069. DOI: 10.3748/wjg.15.4067.

5. Kim BJ, Yoo KH, Li K, Kim MN. Parvovirus B19 infection associated with acute hepatitis in infant. Pediatr Infect Dis J 2009;28(7):667. DOI: 10.1097/INF.0b013e3181a645bd.

6. Sun L, Zhang JC. Acute fulminant hepatitis with bone marrow failure in an adult due to parvovirus B19 infection. Hepatology 2012;55(1):329-330. DOI: 10.1002/hep.24720.

7. Morita E, Nakashima A, Asao H, Sato H, Sugamura K. Human parvovirus B19 nonstructural protein (NS1) induces cell cycle arrest at G1 phase. J Virol 2003;77(5):2915-2921. DOI: 10.1128/jvi.77.5.29152921.2003.

8. Singer AL, Olthoff KM, Kim H, Rand E, Zamir G, Shaked A. Role of plasmapheresis in the management of acute hepatic failure in children. Ann Surg 2001;234(3):418-424. DOI: 10.1097/00000658200109000-00015.

9. Bernal W, Wendon J. Acute liver failure. N Engl J Med 2013;369(26): 2525-2534. DOI: 10.1056/NEJMra1208937.

10. Larsen FS, Schmidt LE, Bernsmeier C, et al. High-volume plasma exchange in patients with acute liver failure: an open randomised controlled trial. J Hepatol 2016;64(1):69-78. DOI: 10.1016/ j.jhep.2015.08.018.

11. Stahl K, Hadem J, Schneider A, Manns MP, Wiesner O, Schmidt BMW, et al. Therapeutic plasma exchange in acute liver failure. J Clin Apher 2019;34(5):589-597. DOI: 10.1002/jca.21737.

12. Maheshwari A, Bajpai M, Patidar GK. Effects of therapeutic plasma exchange on liver function test and coagulation parameters in acute liver failure patients. Hematol Transfus Cell Ther 2019. pii: S25311379(19)30102-6 10.1016/j.htct.2019.05.003. 